\title{
Application Of The Concept And Monitoring Of Robot Line Follwer As a Prototype Of Pekanbaru Trans Metro Bus Towards The Revolution Industry 4.0

\author{
(Penerapan Konsep Dan Monitoring Robot Line Follwer Sebagai \\ Prototipe Bus Trans Metro Pekanbaru Menuju Era Revolusi Industri 4.0)
}

\author{
Anip Febtriko ${ }^{1}$, Wita Yulianti ${ }^{2}$ \\ 1,2 Universitas Abdurrab, Indonesia \\ anip.febtriko@univrab.ac.id
}

\begin{abstract}
Public transportation is a major part of developing an advanced and modern city. Progress in public transportation is needed to be planned and realized to deal with the development of the city together with population and economic growth. The use of the Trans Metro Pekanbaru bus transportation is not in line with the development and progress of the City of Pekanbaru, which wants to be a smart city, where the role of the Internet of Things (IoT) needs to be realized in building smart cities and currently the use of the Trans Metro Pekanbaru bus in Pekanbaru is still becoming a problem. it needs to be resolved like the Trans Metro Pekanbaru bus lane which still uses a shared lane which causes congestion and lack of good traffic regulations. Trans Metro Pekanbaru bus transportation is still weak in terms of arrival and departure times. Trans metro Pekanbaru has not yet been integrated in a system that can be monitored centrally through the application of an application system based on the Global Positioning System (GPS). To overcome this problem, it is necessary to have the Trans Metro Pekanbaru bus transportation in the form of a prototype line follower robot which is a solution to overcome this problem. The purpose of this research is to make the line follower robot as a trans-metro silmulation bus for Pekanbaru become a smart city that is able to serve and facilitate the public's need for public transportation towards the industrial revolution 4.0. Line follower robot is a robot that works by following a line in the form of a road such as a traffic lane, where the robot works using photodiode sensors and ultrasonic sensors as proximity sensors so that it stops automatically at every stop or place where passengers rise and fall. Line follower robots are automatically controlled so programming code and fuzzy algorithms are needed. Line follower robots are also equipped with Closed Circuit Television (CCTV) to determine passenger conditions.
\end{abstract}

Keywords: Line follower robot, GPS, Smart city, Prototype method

\begin{abstract}
Abstrak
Transportasi umum adalah bagian utama dari pengembangan kota yang maju dan modern. Kemajuan transportasi umum diperlukan untuk direncanakan dan direalisasikan untuk menghadapi perkembangan kota bersama dengan pertumbuhan penduduk dan ekonomi. Penggunaan transportasi bus Trans Metro Pekanbaru tidak sejalan dengan perkembangan dan kemajuan Kota Pekanbaru, yang ingin menjadi kota yang cerdas, di mana peran Internet of Things (IoT) perlu diwujudkan dalam membangun kota-kota pintar dan saat ini Penggunaan bus Trans Metro Pekanbaru di Pekanbaru masih menjadi masalah. itu perlu diselesaikan seperti jalur bus Trans Metro Pekanbaru yang masih menggunakan jalur bersama yang menyebabkan kemacetan dan kurangnya peraturan lalu lintas yang baik. Transportasi bus Trans Metro Pekanbaru masih lemah dalam hal waktu kedatangan dan keberangkatan. Trans metro pekanbaru belum terintegrasi dalam sistem yang dapat dipantau secara terpusat melalui penerapan sistem aplikasi berdasarkan Global Positioning System
\end{abstract}


(GPS). Untuk mengatasi masalah yang ada, perlu untuk memiliki transportasi bus Trans Metro Pekanbaru dalam bentuk robot pengikut garis prototipe yang merupakan solusi untuk mengatasi masalah ini. Tujuan dari penelitian ini adalah untuk membuat robot pengikut garis sebagai bus silmulasi trans metro untuk Pekanbaru menjadi kota pintar yang mampu melayani dan memfasilitasi kebutuhan publik akan transportasi publik menuju revolusi industri 4.0. Robot pengikut garis adalah robot yang bekerja dengan mengikuti garis dalam bentuk jalan seperti jalur lalu lintas, di mana robot bekerja menggunakan sensor fotodioda dan sensor ultrasonik sebagai sensor jarak sehingga berhenti secara otomatis di setiap halte atau tempat penumpang naik dan jatuh. Robot pengikut garis dikontrol secara otomatis sehingga kode pemrograman dan algoritma fuzzy diperlukan. Robot pengikut garis juga dilengkapi dengan Closed Circuit Television (CCTV) untuk menentukan kondisi penumpang.

Kata kunci: Robot pengikut garis, GPS, Kota pintar, Metode prototipe 


\section{Pendahuluan}

Transportasi umum memiliki peranan penting dalam pembangunan perekonomian, untuk menuju keberlajutan transportasi umum memerlukan penanganan serius. Transportasi umum merupakan elemen penting dalam perekonomian karena berkaitan dengan distribusi barang, jasa, dan tenaga kerja, serta merupakan inti dari pergerakan ekonomi di kota, berbagai bentuk model transportasi umum dengan karakteristik dan tingkat pelayanan yang diberikan mewarnai perkembangan sistem transportasi umum kota yang seharusnya berorientasi kepada kenyamanan, ketepatan waktu dan keamanan sehingga dapat mengurangi penggunaan kendaraan pribadi.

Pekanbaru sebagai kota lima besar di pulau sumatera mempunyai arus lalu lintas dan mobilitas masyarakat yang tinggi terutama pada saat pagi hari yang merupakan mulainya suatu aktivitas dan sore hari di saat mengakhiri aktivitasnya menyebabkan kendaraan-kendaraan tersendat, dan juga menimbulkan kemacetan. Pada saat ini masyarakat belum menjadikan trans metro pekanbaru sebagai alat transportasi utama untuk beraktifitas dan masih menggunakan kendaraan pribadi sehingga belum terwujudnya kota pekanbaru menjadi smart city yang merupakan agenda pemerintahan kota pekanbaru. Dimana pada saat ini penggunaan bus trans metro pekanbaru di kota pekanbaru masih banyak permasalahan yang perlu diselesaikan seperti jalur jalan bus trans metro pekanbaru yang masih menggunakan jalur bersama dengan kendaraan yang lain, transportasi trans metro pekanbaru masih lemah dalam hal ketepatan waktu kedatangan dan keberangkatan sehingga penumpang mengalami keterlambatan dalam beraktifitas. Semua transportasi bus trans metro pekanbaru belum terintegrasi dalam suatu sistem yang dapat dimonitoring pergerakan trans metro pekanbaru melalui aplikasi yang berbasiskan Global Positioning System (GPS). Perancangan dan pembuataan program ini juga mempertimbangkan latar belakang dari factor manusia atau masyarakat pengguna. Dimana factor manusia atau masyarakat ini mengharapkan adanya bus tranportasi yang cepat dan tepat waktu.

\section{Landasan Teori}

\subsection{Line follower robot}

Line follower robot adalah sebuah alat yang dapat berjalan secara otomatis mengikuti garis berdasarkan perubahan warna pada garis baik hitamdanputih. Hasil dari perubahan warna tersebut menyebabkan nilai pada photodiode berubah sehingga menyebabkan nilai yang masuk kedalam port ADC pada mikrokontroller berubah, dan nilai ADC tersebut yang akan kita oleh menja disebuah input [1].

\subsection{Mikrokontroler}

Mikrokontroler adalah sebuah system computer lengkap dalam satu serpih (chip) yang biasanya digunakan untuk sebuah embedded system (sistem yang dibentuk guna menjelaskan satu atau lebih dari suatu fungsi tertentu secara real time). Mikrokontroler biasanya berukuran kecil karena didesain hanya untuk satu fungsi tertentu pada suatu sistem [3].

\subsection{Driver Motor}

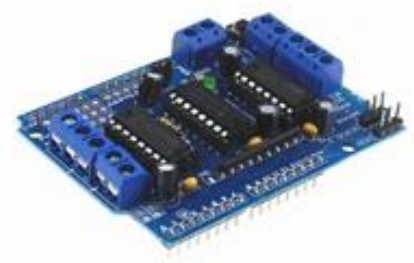

Gambar 2.2 : Driver Motor 
Driver Motor L293D adalah driver yang digunakan untuk arus tinggi. L293 dibuat untuk menyediakan arus yang dapat diarahkan hingga 1 A pada tegangan 4,5 Volt 36 volt [5]. Sedangkan L293D dibuat untuk menyediakan arus yang dapat di arahkan hingga $600 \mathrm{~mA}$ pada tegangan 4,5 volt hingga 36 volt. Kedua driver tersebut didisain untuk dapat mengendalikan beban yanng bersifat induktif seperti relay, solenoid, dc, dan motor steppingbipolar, maupun beban yang mempunyai tegangan tinggi dan arus tinggi dalam penggunaan positif-supply [6].

\subsection{Motor DC}

Motor DC adalah perangkat mesin pertama yang mengkonversi besaran listrik menjadi besaran mekanik [7]. Mengendalikan kecepatan putaran motor DC ada 3 cara antara lain [8]:

1. Metode ON Off.

2. Menggunakan variabel tegangan

3. Menggunakan PWM ( Pulse Width Modulation ).

\subsection{Sensor}

\subsubsection{Sensor Photodiode}

sensor garis di sini adalah suatu perangkat atau alat yang digunakan untuk mendeteksi adanya sebuah garis atau tidak. Sebagai sumber cahaya kita gunakan LED (Light Emiting Diode) yang akan memancarkan cahaya merah [9] dan untuk menangkap pantulan cahaya LED, kita gunakan photodiode. Jikasensor berada diatas garis hitam maka photodiode akan menerima sedikit sekali cahaya pantulan. Tetapi jika sensor berada diatas garisputih maka photodiode akan menerima banyak cahaya pantulan. Berikut adalah ilustrasinya [10] :

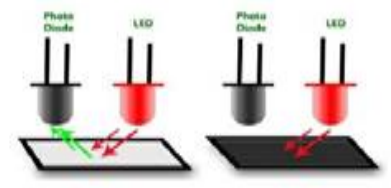

Gambar 2.4 : Sensor Photodiode

\subsubsection{Sensor Ultrasonic}

Sensor ultrasonik adalah sensor yang bekerja berdasarkan prinsip pantulan gelombang suara dan digunakan untuk mendeteksi keberadaan suatu objek tertentu di depannya, frekuensi kerjanya pada daerah di atas gelombang suara dari $40 \mathrm{KHz}$ hingga $400 \mathrm{KHz}$ [11].

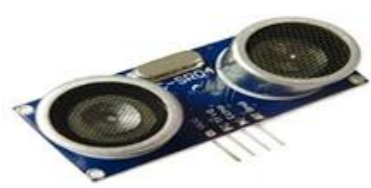

Gambar 2.5 : Sensor Ultrasonik

Sensor ultrasonik terdiri dari dari dua unit, yaitu unit pemancar dan unit penerima. Tegangan bolak-balik yang memiliki frekuensi kerja $40 \mathrm{KHz}-400 \mathrm{KHz}$ diberikan pada plat logam. Struktur atom dari kristal piezoelectric akan berkontraksi (mengikat), mengembang atau menyusut terhadap polaritas tegangan yang diberikan dan ini disebut dengan efek piezoelectric [12].

\subsection{Modul Bluetooth HC-05}

Bluetooth adalah protokol komunikasi wireless yang bekerja pada frekuensi radio $2.4 \mathrm{GHz}$ untuk pertukaran data pada perangkat bergerak seperti PDA, laptop, HP, dan lain-lain [13]. Salah satu hasil contoh modul Bluetooth yang paling banyak digunakan adalah tipe HC-05. Untuk gambar module bluetooth dapat dilihat pada gambar 2.7 dibawah ini [14]: 


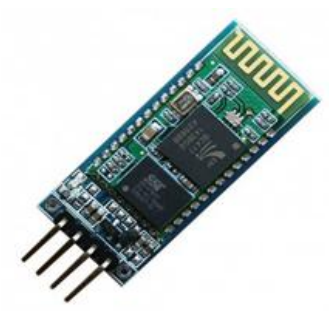

Gambar 2.6 : Modul Bletooth HC-05

\subsection{Logika Fuzzy}

Logika fuzzy merpakan salah satu komponen pembentuk soft computing. Logika fuzzy pertama kali diperkenalkan oleh Prof. LotfA. Zadeh pada tahun1965. Dasar logika fuzzy adalah teori himpunan fuzzy[15]. Pada teori himpunan fuzzy, perananan derajat keanggotaan sebagai penentu keberadaan elemen dalam suatu himpunan sangatlah penting. Nilai keanggotaan atau derajat keanggotaan atau membership function menjadi ciri utama dan penalaran dengan logika fuzzy tersebut logika fuzzy adalah suatu cara yang tepat untuk memetakan ruang input ke dalam suatu ruang output.

\subsection{Global Positioning System (GPS).}

GPS adalah sistem navigasi yang berbasiskan satelit yang saling berhubungan yang berada di orbitnya. Untuk dapat mengetahui posisi seseorang maka diperlukan alat yang diberinama GPS reciever yang berfungsi untuk menerima sinyal yang dikirim dari satelit GPS. Posisi diubah menjadi titik yang dikenal dengan nama Way-point nantinya akan berupa titik-titik koordinat lintang dan bujur dari posisi seseorang atau suatu lokasi kemudian di layar pada peta elektronik [16].

\section{Metodologi}

Bagian ini dilengkapi dengan diagram alir penelitian pada gambar 3.1 yang menggambarkan apa yang sudah dilaksanakan dan yang akan dikerjakan selama waktu yang diusulkan, mulai dari awal bagaimana proses dan luarannya, dan indikator capaian yang ditargetkan.

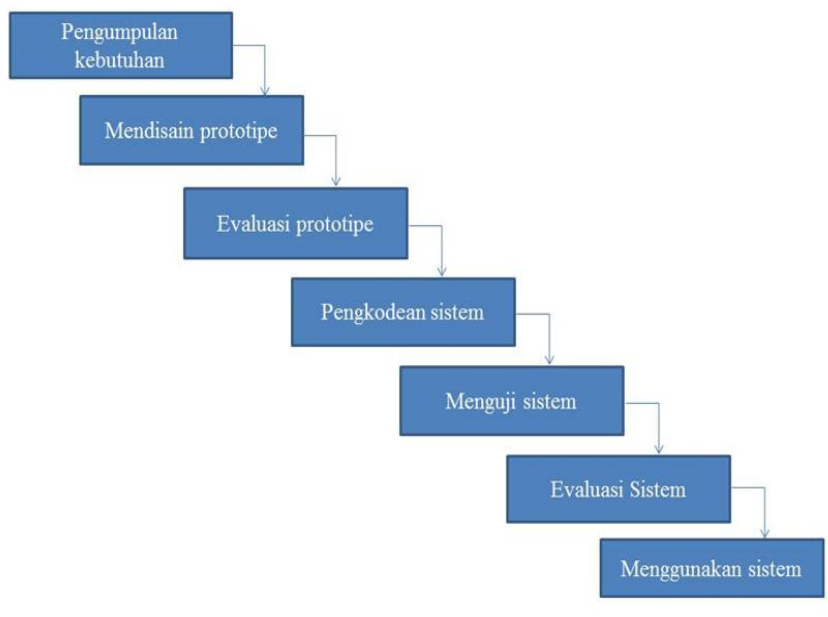

Gambar 3.1 Tahapan Metode Prototipe

3.1. Pengumpulan kebutuhan

Pengumpulan kebutuhan merupakan kegiatan untuk menganalisa prototipe yang akan dirancang. Kebutuhan yang diperlukan dalam pembuatan prototipe adalah sebagai berikut :

a. Studi Pustaka 
Studi pustaka perlu dilakukan untuk mendapatkan sumber teori yang berkaitan dengan permasalahan dalam penelitian dengan cara mempelajari beberapa sumber pustaka/referensi primer yang relevan dan dengan mengutamakan hasil penelitian pada jurnal ilmiah dan/atau paten yang terkini.

b. Wawancara

Pada tahap ini akan dilakukan wawancara ke Dinas Perhubungan dan Pemerintahan Kota yang berkaitan dengan infrastrktur lalu lintas untuk mengetahui kondisi lapangan yang dijadikan pembuatan peta jalur lintasan line follower robot.

3.1.Disain prototipe bus trans metro pekanbaru

Desain sistem yang dilakukan dan dirancangan pada pelitian ini dapat diuraikan sebagai berikut:

1. Line follower robot

Gambar di bawah ini merupakan desain dari robot line follower dengan adanya arduino sebagai mikrokontroler untuk mengendalikan robot tersebut dengan dilengkapi dengan GPS. Robot ini ada beberapa rangkaian yang dibuat seperti berikut ini : Rangkaian Sensor, Rangkaian Komperator, Rangkaian Powersuply, Rangkaian Motor Driver, Rangkaian GPS, Rangkaian Controller

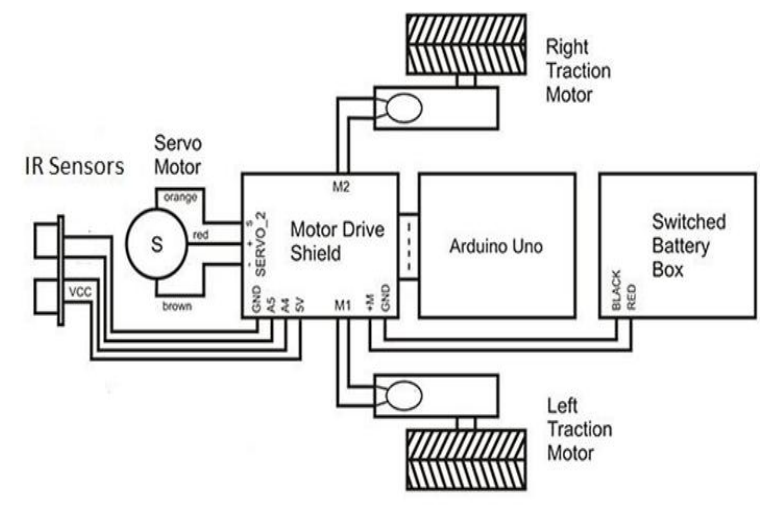

Gambar 3.2 : Disain prototipe bus trans metro pekanbaru

\section{Aplikasi monitoring}

Aplikasi monitoring ini bertujuan untuk melihat dan memantau dari pergerakan robot line follower dimana robot ini dengan nama robot trans metro pekanbaru. Aplikasi ini membaca GPS yang ada di robot tersebut, karena fungsi GPS itu sendiri adalah untuk mengetahui titik koordinat posisi atau keberadaan suatu objek yang diletakan pada objek itu sendiri, disini objeknya adalah robot line follower. Berikut ini adalah desain atau rancangan dari aplikasi monitoring robot line follower sebagaimana terlihat dari gambar berikut ini. 


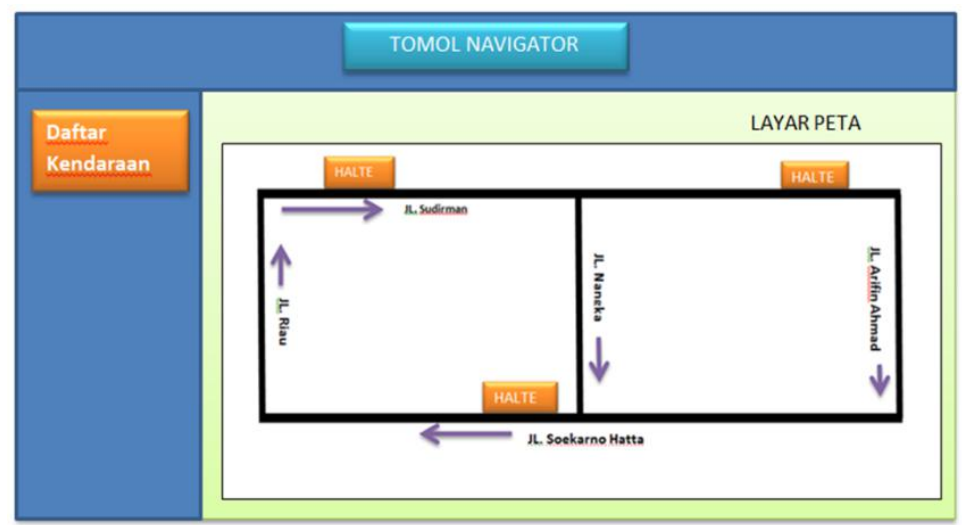

Gambar 3.4 : AplikasimonitoingLine Follower Robot

\subsubsection{Evaluasi prototipe}

Pembuatan prototipe line follower robot perlu dilakukan evaluasi dalam pembuatannya. Bentuk evaluasi yang dilakukan adalah sebagai berikut :

1. Penyesuaian bentuk sasis dengan rangkaian atau komponen yang lain, supaya ada keseimbangan dalam pergerakan robot.

2. Mengevaluasi gambar rancangan dalam pembuatan layout PCB.

\subsubsection{Pengkodekan sistem}

Dalam tahap ini akan dilakukan pembuatan koding program dengan menggunakan bahasa pemrograman $\mathrm{C}$ dan algoritma fuzzy.

\subsubsection{Menguji sistem}

Untuk mengetahui hasil perancangan prototipe perlu dilakukan pengujian dengan tahapan sebagai berikut :

1. Pengujian terhadap sensor dengan mengetahui indikator lampu yanga ada dirangkaian sensor. Board ini terdiri dari 16 sensor photodioda, 16 LED, 2 transistor BD139 sebagai switcing sensor dan resistor.

2. Pengujian terhadap rangkaian driver motor merupakan bagian modul yang berfungsi sebagai kendali motor DC. Board ini terdiri dari 4 P-Chanel Mosfet, 4 N-Chanel Mosfet, 4 buah optocopler, IC TTL NOT, dioda dan resistor.

3. Pengujian terhadap mikrokontroler ATMega yang terdiri dari sistem minimum mikrokontroler ATmega328 display LCD, expansi Port mikrokontroler, komunikasi serial, power supply 5 volt menggunakan IC regulator 7805 .

\subsubsection{Evaluasi Sistem}

Tahapan evaluasi sistem ini sangat diperlukan untuk mengetahui kemungkinan keruksakan kinerja sistem robot. Cara yang dilakukan untuk mengevaluasi adalah mengukur kecepatan, daya tangkap pembacaan sensor dan daya power suply yang dibutuhkan.

\subsubsection{Menggunakan sistem}

Berikut ini dijelaskan penggunaan atau cara kerja system bus trans metro pekanbaru :

1. Setiap bus akan diaktifkan melalui aplikasi dengan setingan waktu tertentu dan waktu yang berbeda.

2. Bus ini akan berhenti disetiap halte atau tempat naik dan turunnya penumpang.

3. Waktu tunggu bus dan berangkat di halte telah ditetapkan untuk mencapai tujuan ketepatan waktu. 


\section{Hasil dan Diskusi}

\subsection{Hasil Desain Robot}

Berikut ini ditunjukkan hasil desain perangkat keras dalam bentuk robot Trans Metro Pekanbaru dalam bentuk mobil roda tiga yang disimulasikan sebagai model bus:

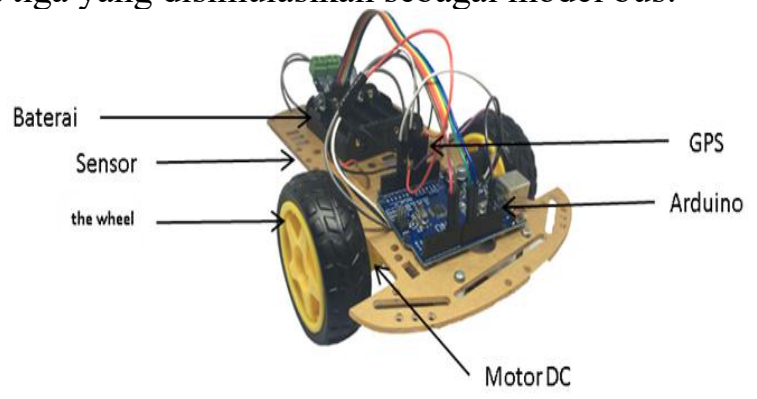

Gambar 4.1 : Robot Line Follower

Dari Gambar 4.1, bentuk fisik dari desain bus robot dengan sensor fotodioda dapat dilihat. Peneliti menggunakan sensor fotodioda dengan posisi sensor melengkung di bagian depan robot yang dimaksudkan untuk membaca garis dari lintasan miniatur kawasan Trans Metro Pekanbaru dan 1 sensor jarak yang terletak di bagian depan robot. Sensor jarak digunakan agar robot dapat mengetahui apakah ada penghalang di depan atau tidak saat berjalan.

Komponen-komponen berikut ada di dalam robot:

1) Sakelar Daya: Sakelar utama untuk seluruh sistem kelistrikan.

2) Left Gearbox: Sistem mekanis utama untuk sisi kiri

3) Baterai: Sumber listrik robot.

4) Gearbox kanan: Sistem mekanis utama di sebelah kanan

5) Port ISP: Port untuk menghapus / mengisi program

6) Sensor: Sensor depan, pembaca jalur utama

7) Distance Sensor: Sensor untuk memeriksa hambatan atau tidak di trek.

4.2 Desain Program

Berikut ini dijelaskan perancangan program menggunakan Arduino Uno dengan logika fuzzy yang diterapkan dalam pemrograman.

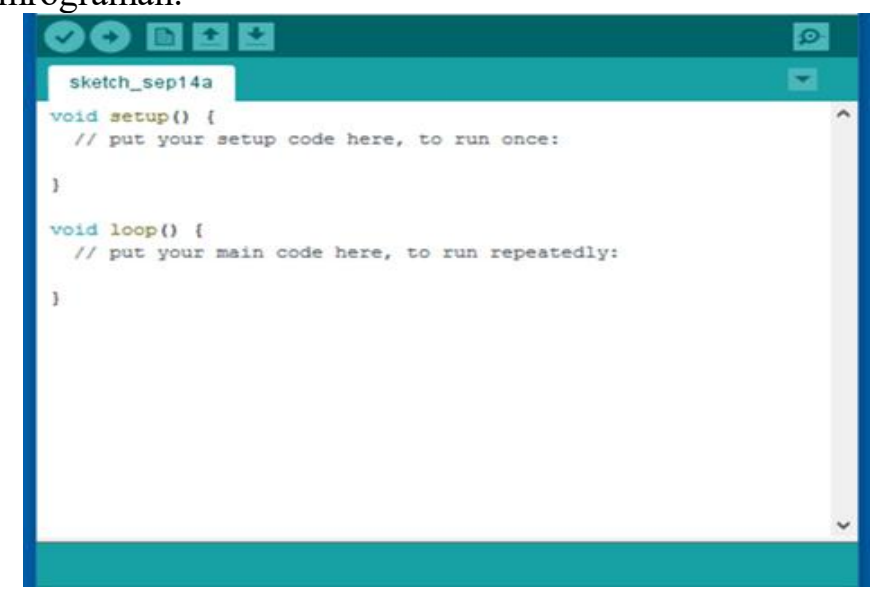

Gambar 4.2 Desain Program Arduino

\subsection{Pengujian GPS}




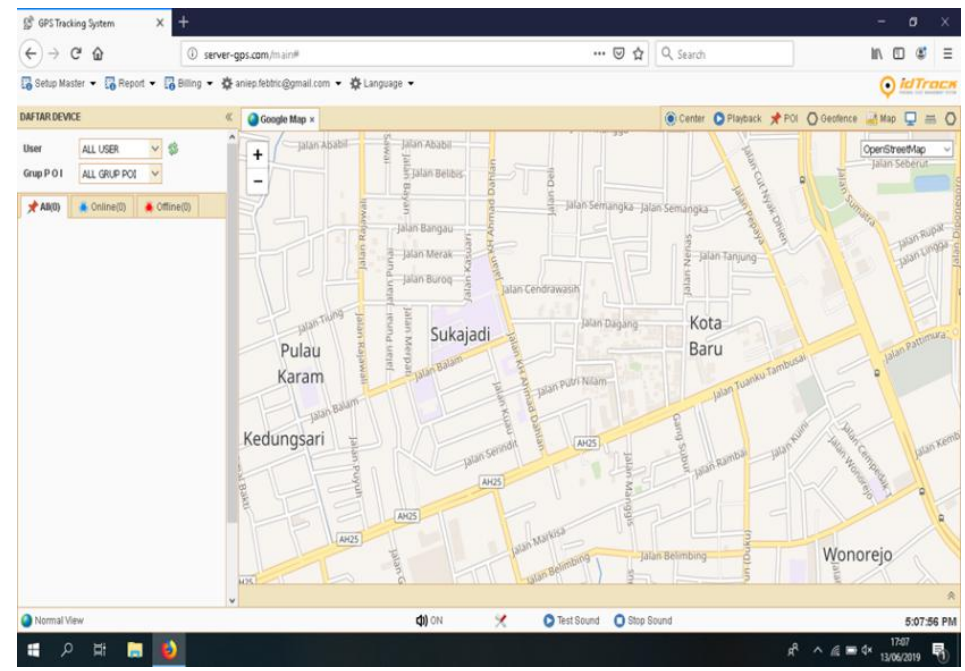

Gambar 4.3 Gambar GPS

Pengujian menggunakan portal atau alamat situs web adalah http://server-gps.com. Keberadaan situs web ini memudahkan untuk memantau aktivitas dan silmulasi pengikut garis trans metro robot pekanbaru. Gambar berikut melihatkan posisi dari robot tersebut dengan menggunakan GPS dan alat ini diletakan disetiap robot yang digunakan. Pembacaan titik koordinat inilah yang merupakan kinerja dari GPS, sehingga bekerja dan terbaca oleh aplikasi server tersebut dan bisa dilihat oleh aplikasi yang telah dibuat. Dimana aplikasi ini adalah telah ada di website dan bisa di akses oleh admin sebagai pengontrol dan memonitoring kegiatan bus trans metro pekanbaru.

\subsection{Pengujian Sistem}

Pengujian sistem adalah proses mengeksekusi sistem perangkat keras dan perangkat lunak untuk menentukan apakah sistem tersebut sesuai dan sesuai dengan apa yang diinginkan peneliti. Pengujian dilakukan dengan melakukan eksperimen untuk melihat kemungkinan kesalahan yang terjadi dari setiap proses.

Tabel 1 :Hasil Percobaan Sensor

\begin{tabular}{rc}
\hline Sensor Input & Robot Motion Respon \\
\hline 00111100 & Advanced \\
00111000 & Advanced \\
00001100 & Turn right \\
00000100 & Turn right \\
00110000 & Turn left \\
\hline
\end{tabular}

Pengujian sistem yang digunakan adalah Black Box. Pengujian Black Box adalah pengujian perangkat dalam hal spesifikasi fungsional tanpa menguji desain dan kode program. Tes ini dimaksudkan untuk mengetahui apakah fungsi dan output sudah seperti yang diinginkan. Dalam melakukan pengujian, tahapan yang dilakukan untuk pertama kalinya adalah pengujian perangkat input, yaitu pengujian sensor yang ada termasuk sensor fotodioda. Kemudian lakukan pengujian keseluruhan sistem kontrol robot.

\section{Kesimpulan}

Berdasarkan hasil penelitian yang telah dilakukan, kesimpulannya adalah sebagai berikut:

1. Robot trans metro pekanbaru telah berhasil dirancang dan dibuat menggunakan mikrokontroler Arduino UNO dengan sistem penggerak berupa roda yang menggunakan motor DC dan dilengkapi dengan beberapa sensor seperti sensor fotodioda. 
2. Hasil uji sensor Photodioda memiliki nilai tetap sehingga ketika percobaan robot dapat berjalan dengan normal dan baik.

3. Pengujian sistem robot transportasi secara keseluruhan menunjukkan bahwa robot dapat menjalankan misinya untuk dapat berjalan di sepanjang garis sesuai dengan pembacaan sensor dengan logika fuzzy yang telah diterapkan.

\section{Referensi}

[1] K. Alisher, K. Alexander, and B. Alexandr, "Control of the mobile robots with ROS in robotics courses," Procedia Eng., vol. 100, no. January, pp. 1475-1484, 2015.

[2] S. J. Nasuto and Y. Hayashi, "Anticipation: Beyond synthetic biology and cognitive robotics," BioSystems, vol. 148, pp. 22-31, 2016.

[3] Govinda K., "Design of Smart Meter Using Atmel 89S52 Microcontroller," Procedia Technol., vol. 21, pp. 376-380, 2015.

[4] B. Lahfaoui, S. Zouggar, B. Mohammed, and M. Larbi, "Real time study of P \& O MPPT control for small wind PMSG turbine systems using Arduino microcontroller," Energy Procedia, vol. 111, no. September 2016, pp. 1000-1009, 2017.

[5] X. Liu and D. Zhao, "The simulation of stepping motor under two kinds of condition," Procedia Eng., vol. 23, pp. 464-467, 2011.

[6] F. Q. Qi, X. D. Jing, and K. He, "Control system of stepper motor based on roundness and cylindricity measuring virtual instrument," Procedia Eng., vol. 15, pp. 2281-2285, 2011.

[7] Z. Bitar, S. Al Jabi, and I. Khamis, "Modeling and simulation of series DC motors in electric car," Energy Procedia, vol. 50, pp. 460-470, 2014.

[8] O. V. Shepovalova and A. T. Belenov, "Investigation of DC Motors Mechanical Characteristics with Powered by Comparable Capacity PV Array," Energy Procedia, vol. 119, pp. 990-994, 2017.

[9] D. Gäbler, C. Henkel, and S. Thiele, "CMOS Integrated UV-Photodiodes," Procedia Eng., vol. 168, pp. 1208-1213, 2016.

[10] S. Zhao, G. Lioliou, and A. M. Barnett, "Temperature dependence of commercial 4H-SiC UV Schottky photodiodes for X-ray detection and spectroscopy," Nucl. Instruments Methods Phys. Res. Sect. A Accel. Spectrometers, Detect. Assoc. Equip., vol. 859, no. January, pp. 76-82, 2017.

[11] N. Nordin, M. Idroas, Z. Zakaria, and M. N. Ibrahim, "Design and Fabrication of Ultrasonic Tomographic Instrumentation System for Inspecting Flaw on Pipeline," Procedia Manuf., vol. 2, no. February, pp. 313-318, 2015.

[12] K. G. Panda, D. Agrawal, A. Nshimiyimana, and A. Hossain, "Effects of environment on accuracy of ultrasonic sensor operates in millimetre range," Perspect. Sci., vol. 8, pp. 574-576, 2016.

[13] R. Lodha, S. Gupta, H. Jain, and H. Narula, "Bluetooth Smart based attendance management system," Procedia Comput. Sci., vol. 45, no. C, pp. 524-527, 2015.

[14] S. Sandhya, K. A. Sumithra Devi, and S. Paramasivam, "Augmenting Bluetooth Security by Behavior Based User Categorization,” Procedia Comput. Sci., vol. 57, pp. 1424-1431, 2015.

[15] N. Rai and B. Rai, "Control of fuzzy logic based PV-battery hybrid system for stand-alone DC applications," J. Electr. Syst. Inf. Technol., vol. 5, no. 2, pp. 135-143, 2018.

[16] M. J. Camp, J. L. Rachlow, R. Cisneros, D. Roon, and R. J. Camp, "Evaluation of Global Positioning System telemetry collar performance in the tropical Andes of southern Ecuador," Nat. e Conserv., vol. 14, no. 2, pp. 128-131, 2016. 
Anip Febtriko ${ }^{1}$, Wita Yulianti ${ }^{2}$ 